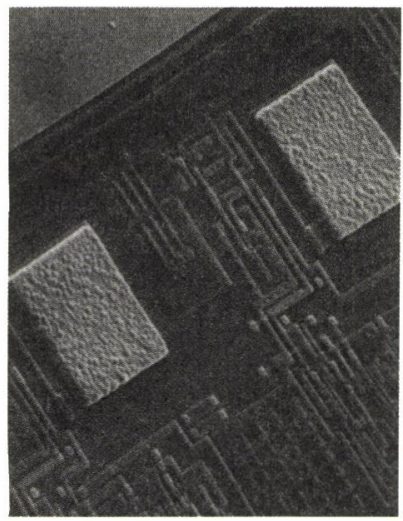

\title{
誘電体セラミックの現状と将来
}

\author{
Dielectric Ceramics, Today and Tomorrow
}

\section{萬代 治文*＼cjkstart脇野喜久男*}

\section{1. 電子部品, 機器の動向と誘電体材料}

情報通信システムの動的な発展に伴って, 電子機器, 部品に対し, 省電エネルギー, 高機能, 小型軽量, 高周 波化と高信頼性といった多くのことが求められている。

Fig.1はこのような要請に沿ったモジュー ル，部品の技術動向を示す。こうした技術 動向の中で誘電体材料には次のようなこと が要求されている。

(1)小型高密度化

高誘電率材料, 肉薄化（耐電圧の向上, 製造技術）

多層材料, 異物質の多層化, 多層配線

薄膜材料, 多層薄膜材料

(2)高周波化

低誘電率, 低損失材料

低温焼結材料

卑金属電極材との共焼結

高誘電率，高周波特性の改善

低温焼結材料

卑金属電極材との共焼結

(3)高信頼性

耐電圧, 耐湿性, 経時変化率などの特性 向上

\section{2. 誘電体材料の現状}

\footnotetext{
* Harufumi Mandai, Kikuo Wakino 村田製作所 /MURATA MFG.CO.,LTD.
}

誘電体材料は，大きく分けてコンデンサ材料，多層厚 膜材料, 高周波誘電体材料, (高周波) 基板材料, 高周波 デバイス材料などに分類される。

\section{1 コンデンサ材料 ${ }^{1), 21}$}

セラミックコンデンサは, 良好な高周波特性, 低損失,

\section{Modules}

More miniaturized and higher density

- Ceramic multilayer substrates

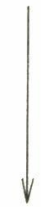

For higher frequency use

- Low dielectric constant, low temperature fireable ceramic materials

(High frequency ceramic substates)

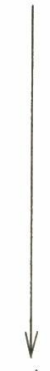

Thick film passive elements

(Thick film materials)

Buriedpassive elements into substrates (Buried capacitor materials)

Fig.1 Trend of modules and components.

\section{Components}

More miniaturized for more capacity

- High dielectric constant materials

- Thin film materials (Capacitors)

For higher frequency use

- High dielectric constant, low-loss materials (High frequency dielectric materials)

- High dielectric constant, low temperature fireable materials

(High frequency devices) (Capacitors)

Limit of passive components mounting $\left[\begin{array}{l}\text { Small size } \\ \text { Reliability }\end{array}\right]$ $S H M$ 会誌 
Tab.1 Electrical properties of dielectric ceramics for temperature compensation ${ }^{1)}$

\begin{tabular}{l|r|c}
\hline & $\begin{array}{c}\text { Dielectric } \\
\text { constant }\end{array}$ & $\begin{array}{c}\text { Thermal coefficient } \\
\text { of capacitance } \\
\text { (ppm } /{ }^{\circ} \mathrm{C} \text { ) }\end{array}$ \\
\hline $\mathrm{Mg}_{2} \mathrm{TiO}_{4}$ & 6.4 & +130 \\
$\mathrm{MgAl}_{2} \mathrm{O}_{4}$ & 7.5 & +130 \\
$\mathrm{MgTiO}_{3}$ & 13 & +100 \\
$\mathrm{ZrO}_{2}$ & 18 & +170 \\
$\mathrm{SrZrO}_{3}$ & 30 & +140 \\
$\mathrm{La}_{2} \mathrm{Ti}_{2} \mathrm{O}_{7}$ & 37 & +60 \\
$\mathrm{Nd}_{2} \mathrm{Ti}_{2} \mathrm{O}_{7}$ & 39 & +90 \\
$\mathrm{CaSiTiO}_{5}$ & 45 & +1200 \\
$\mathrm{Bi}_{1.8} \mathrm{La}_{0.2} \mathrm{Ti}_{2} \mathrm{O}_{7}$ & 130 & +1035 \\
\hline $\mathrm{ZnTiO}_{3}$ & 38 & -60 \\
$\mathrm{Bi}_{2} \mathrm{Ti}_{2} \mathrm{O}_{7}$ & 104 & -150 \\
$\mathrm{TiO}_{2}$ & 100 & -750 \\
$\mathrm{CaTiO}_{3}$ & 168 & -1850 \\
$\mathrm{SrTiO}_{3}$ & 232 & -3000 \\
\hline
\end{tabular}

Tab.2 Electrical properties of complex Perovskitetype dielectric ceramics containing lead ${ }^{2)}$

\begin{tabular}{ll|c|c}
\hline & \multicolumn{2}{|c|}{$\begin{array}{c}\text { Curie temperature } \\
\left({ }^{\circ} \mathrm{C}\right)\end{array}$} & $\begin{array}{l}\text { Dielctric } \\
\text { constant (Max) }\end{array}$ \\
\hline $\mathrm{Pb}\left(\mathrm{Mg}_{1 / 3} \mathrm{Nb}_{2 / 3}\right)$ & $\mathrm{O}_{3}$ & -12 & 15000 \\
$\mathrm{~Pb}\left(\mathrm{Zn}_{1 / 3} \mathrm{Nb}_{2 / 3}\right)$ & $\mathrm{O}_{3}$ & 140 & 22000 \\
$\mathrm{~Pb}\left(\mathrm{Ni}_{1 / 3} \mathrm{Nb}_{2 / 3}\right)$ & $\mathrm{O}_{3}$ & -120 & 4000 \\
$\mathrm{~Pb}\left(\mathrm{Co}_{1 / 3} \mathrm{Nb}_{2 / 3}\right)$ & $\mathrm{O}_{3}$ & -70 & 6000 \\
$\mathrm{~Pb}\left(\mathrm{Fe}_{1 / 2} \mathrm{Nb}_{1 / 2}\right)$ & $\mathrm{O}_{3}$ & 114 & 12000 \\
$\mathrm{~Pb}\left(\mathrm{Mg}_{1 / 3} \mathrm{Ta}_{2 / 3}\right)$ & $\mathrm{O}_{3}$ & -98 & 7000 \\
$\mathrm{~Pb}\left(\mathrm{Ni}_{1 / 3} \mathrm{Ta}_{2 / 3}\right)$ & $\mathrm{O}_{3}$ & -180 & 2500 \\
$\mathrm{~Pb}\left(\mathrm{Co}_{1 / 3} \mathrm{Ta}_{2 / 3}\right)$ & $\mathrm{O}_{3}$ & -140 & 4000 \\
$\mathrm{~Pb}\left(\mathrm{Fe}_{2 / 3} \mathrm{~W}_{1 / 2}\right)$ & $\mathrm{O}_{3}$ & -30 & 10000 \\
$\mathrm{~Pb}\left(\mathrm{Fe}_{2 / 3} \mathrm{~W}_{1 / 3}\right)$ & $\mathrm{O}_{3}$ & -95 & 9000 \\
$\mathrm{~Pb}\left(\mathrm{Mg}_{1 / 2} \mathrm{~W}_{1 / 2}\right)$ & $\mathrm{O}_{3}$ & 39 (AFE) & 250 \\
$\mathrm{~Pb}\left(\mathrm{Co}_{1 / 2} \mathrm{~W}_{1 / 2}\right)$ & $\mathrm{O}_{3}$ & 32 (AFE) & 250 \\
\hline
\end{tabular}

高信頼性, 低価格が特徵である。LSI（現在 $5.5 \mathrm{~V}$, 将来 は $3.3 \mathrm{~V}$ 以下) の動作電圧が低くなるに伴って, 固体電 解コンデンサに匹敵する容量体積比の製品も現れている。 現在使用されているコンデンサは, 温度補償用と高誘電 率用に大分類される。

温度補償用コンデンサ材料は一般に $\varepsilon_{r}=350$ 程度以 下で, その温度変化率 (TCC の偏差) が小さく, +100 1,500 (-4,700) $\mathrm{ppm} /{ }^{\circ} \mathrm{C}$ のもが自由に得られること, 高周波での誘電損失 $(\tan \delta)$ が小さいという特徵があ る。代表的なものとして, $\mathrm{MgTiO}_{3}, \mathrm{Nd}_{2} \mathrm{Ti}_{2} \mathrm{O}_{3}$ などがあ る。

Tab.1 に温度補償用コンデンサ材料とその特性を示す。 高誘電率系材料にはチタン酸バリウム系，鉛複合ぺロ ブスカイト系があり, 常温での $\varepsilon_{r}$ は, 1,000〜 10,000を示 Vol.9, No.1

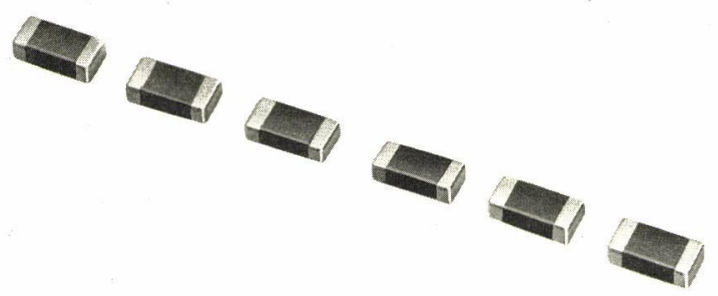

Fig.2 Monolithic ceramic capacitor.

す。特に鉛複合ぺロブスカイト系は, 高誘電率 $\left(\varepsilon_{r}=\right.$ 4,000 ～10,000) であり， かつ誘電率温度変化が小さいと いう特色をもっているので, 高誘電率材料として最近普 及してきた。その鉛複合ペロブスカイト系材料の特性を

Tab.2に示す。

セラミックコンデンサの小型大容量化については, (1) 高誘電率セラミックの開発-鉛複合ペロブスカイト系材 料, (2)誘電体の薄層化-異常粒成長の抑制と粒径分布の均 一化, 気孔率の低減, 気孔の微細化を目標としたプロセ 又開発が活発に行われている。

一方, 低価格化については, 低価格電極の使用一 (1) Ag 系電極の使用：低温焼結誘電体材料の開発（鉛複合ぺロ ブスカイト系), (2)卑金属 $(\mathrm{Ni}, \mathrm{Cu})$ 電極の使用：耐還元 性のある誘電体材料の開発 $(\mathrm{Ba}, \mathrm{Sr}) \mathrm{O}-\mathrm{SiO}_{2}-\mathrm{ZrO}_{2}$ 系) がなされている。Fig.2に Ni 電極を用いたチップ積層コ ンデンサを示す。

最近では, 1005 タイプ $(1.0 \times 0.5 \mathrm{~mm})$ の積層チップコ ンデンサが量産され，実験室的には， $0.8 \times 0.4 \mathrm{~mm} る い$ はそれ以下のものもできている(実装技術的な問題を残 しているが)。

\section{2 厚膜材料}

厚膜誘電体は，(アルミナ) 基板上に厚膜工法を利用し てオーバーコート，クロスオーパー，多層配線の絶縁層， コンデンサなどとして抵抗ペース卜と共に，電子回路を 構成するのに利用されている。コンデンサを形成するた めの厚膜材料の特徵をTab.3 に示す。厚膜コンデンサ は, $\varepsilon_{r}=10 \sim 100$ 程度の低誘電率系と, $\varepsilon_{r}=500 \sim 1,500$ 程度の高誘電率系に分けられる。低誘電率コンデンサは 低誘電損失, 一定の容量温度係数という特徵を生かし温 度補償用に，また高誘電率系コンデンサは高容量を得や すいので，バイパスコンデンサとして用いられる。

厚膜コンデンサを形成するための誘電体ペーストは, 誘電体セラミック粉末とガラスフリット（ホウケイ酸ビ スマスガラス）の混合物からなるものと，ガラスフリッ 卜(ホウケイ酸鉛ガラス) のみのものがある。最近，鉛 
Tab.3 Properties of dielectric ceramics paste ${ }^{3}$

\begin{tabular}{c|c|c|c|c}
\hline & $\begin{array}{c}\text { Dielectric } \\
\text { constant }(\mathrm{K}) \\
1 \mathrm{kHz} \cdot 25^{\circ} \mathrm{C}\end{array}$ & $\begin{array}{c}\tan \delta \\
(\%) \\
1 \mathrm{kHz} \cdot 25^{\circ} \mathrm{C}\end{array}$ & $\begin{array}{c}\text { Thickness } \\
(\mu \mathrm{m})\end{array}$ & $\begin{array}{c}\text { Firing } \\
\text { temperature } \\
\left({ }^{\circ} \mathrm{C}\right)\end{array}$ \\
\hline \multirow{4}{*}{$\mathrm{A}$} & $8 \sim 10$ & $<0.4$ & 45 & $900 \sim 1000$ \\
& $40 \sim 60$ & $<2.0$ & 45 & $900 \sim 1000$ \\
& $175 \sim 325$ & $<5.0$ & 45 & $950 \sim 1050$ \\
& $350 \sim 650$ & $<5.0$ & 45 & $950 \sim 1050$ \\
& $700 \sim 1300$ & $<5.0$ & 45 & $950 \sim 1050$ \\
& $1500 \sim 2000$ & $<5.0$ & 45 & $950 \sim 1050$ \\
\hline \multirow{3}{*}{$\mathrm{B}$} & $40 \sim 60$ & $<2.0$ & 45 & $875 \sim 900$ \\
& $175 \sim 325$ & $<3.0$ & 45 & $875 \sim 900$ \\
\hline & $9 \sim 12$ & $<0.3$ & 40 & $850 \sim 1050$ \\
& $35 \sim 50$ & $<1.5$ & 40 & $850 \sim 1050$ \\
$\mathrm{C}$ & $350 \sim 500$ & $<2.0$ & 45 & $850 \sim 1050$ \\
& $800 \sim 1200$ & $<3.5$ & 45 & $850 \sim 1050$ \\
& $1100 \sim 1500$ & $<2.0$ & 45 & $850 \sim 1050$ \\
\hline
\end{tabular}

系複合ペロブスカイト $\left(\mathrm{Pb}\left(\mathrm{Fe}_{2 / 3} \mathrm{~W}_{1 / 3}\right) \mathrm{O}_{3}-\mathrm{Pb}\left(\mathrm{Fe}_{1 / 2}\right.\right.$ $\left.\left.\mathrm{Nb}_{1 / 2}\right) \mathrm{O}_{3}\right)$ 系誘電体材料は $850^{\circ} \mathrm{C} \sim 1,000^{\circ} \mathrm{C}$ で焼結し, $\varepsilon_{r}$ が 2,000 を超えるという特徴に注目し, この材料の厚膜 コンデンサへの忍用が現在進められている。

実用するに当たり，多層厚膜方式のみで回路モジュー ルを作るか，一部チップ部品を採用した混成集積回路に するかは, コスト，大きさ，設計，製造の容易さなどを

Tab.4 Electrical properties of dielectric ceramics for resonator ${ }^{1)}$

\begin{tabular}{l|r|r|c}
\hline & $\varepsilon_{r}$ & $\begin{array}{r}Q \cdot f \\
(\mathrm{GHz})\end{array}$ & $\begin{array}{c}\tau_{f} \\
\left(\mathrm{ppm} /{ }^{\circ} \mathrm{C}\right)\end{array}$ \\
\hline $\mathrm{MgTiO}_{3}-\mathrm{CaTiO}_{3}$ & 21 & 55000 & 0 \\
$\mathrm{Ba}(\mathrm{Sn}, \mathrm{Mg}, \mathrm{Ta}) \mathrm{O}_{3}$ & 25 & 200000 & 0 \\
$\mathrm{Ba}(\mathrm{Zn}, \mathrm{Nb}) \mathrm{O}_{3}-\mathrm{Ba}(\mathrm{Zn}, \mathrm{Ta}) \mathrm{O}_{3}$ & 30 & 120000 & 0 \\
$\mathrm{Ba}(\mathrm{Zr}, \mathrm{Zn}, \mathrm{Ta}) \mathrm{O}_{3}$ & 30 & 100000 & 0 \\
$(\mathrm{Zr}, \mathrm{Sn}) \mathrm{TiO}_{4}$ & 38 & 50000 & 0 \\
$\mathrm{Ba}_{2} \mathrm{Ti}_{9} \mathrm{O}_{20}$ & 40 & 35000 & 0 \\
$\mathrm{BaO}_{2} \mathrm{PbO}-\mathrm{Nb}_{2} \mathrm{O}_{3}-\mathrm{TiO}_{2}$ & 90 & 5000 & 0 \\
\hline
\end{tabular}

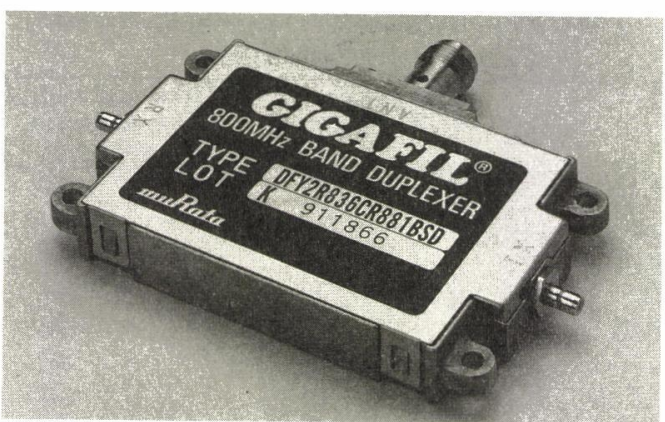

Fig.3 Microwave filter.

考慮して，選択される。

\section{3 高周波誘電体材料 5 ),6)}

BS, CS など, 衛星通信, 携帯電話器など移動体通信用 に用いられているマイクロ波誘電体共振材料に要求され る特性は, 誘電損失ならびに誘電率の温度変化の小さい ことである。現在得られている材料は $\varepsilon_{r}=20 \sim 90, Q$. $f(\mathrm{GHz})=5,000 \sim 400,000, \tau_{r}=0 \pm 0.1 \mathrm{ppm} /{ }^{\circ} \mathrm{C}$ に達 している。材料系としては, $\mathrm{MgTiO}_{3}-\mathrm{CaTiO}_{3}, \mathrm{BaO}-\mathrm{PbO}$ $-\mathrm{Nb}_{2} \mathrm{O}_{3}-\mathrm{TiO}_{2}$ 系等がある。

Tab.4に代表的な誘電体共振器材料の特徴を示す。

主に, マイクロ波フィルタ, オッシレー夕に用いられ ている。Fig.3にマイクロ波フィルタを示す。

今後は MMIC と厚膜, 薄膜多層基板などと組み合わ せたモジュールの開発が期待されている。

\section{4 (高周波) 基板材料7),8),9)}

ハイブリッド ICの高密度化, 多機能化に伴って, 低温 焼結基板材料が開発された。低温焼結基板材料は, 850 1 $1,000^{\circ} \mathrm{C}$ 以下で焼結できるので, $\mathrm{Cu}, \mathrm{Ag}, \mathrm{Ag} / \mathrm{Pd}$ と同時焼成が可能である。高伝導性の $\mathrm{Ag}, \mathrm{Cu}$ を使った 多層配線，また最近では，抵抗ぺーストとの同時焼成，

Tab.5 Comparison of material characteristics of various low temperature cofired multilayered ceramics ${ }^{7,8)}$

\begin{tabular}{|c|c|c|c|c|c|c|c|}
\hline & $\begin{array}{c}\text { Cordierite } \\
\text {-Glass }\end{array}$ & $\begin{array}{c}\text { Qurtz Glass } \\
\text {-Glass }\end{array}$ & $\begin{array}{c}\text { Alumina } \\
\text {-Glass }\end{array}$ & $\begin{array}{c}\mathrm{BaO}-\mathrm{Al}_{2} \mathrm{O}_{3} \\
-\mathrm{SiO}_{2}\end{array}$ & $\mathrm{BaSn}\left(\mathrm{BO}_{3}\right)_{2}$ & $\begin{array}{l}\mathrm{ZnO}-\mathrm{MgO} \\
-\mathrm{Al}_{2} \mathrm{O}_{3}-\mathrm{SiO}_{2}\end{array}$ & $\begin{array}{l}\text { Alumi n a PbO } \\
-\mathrm{B}_{2} \mathrm{O}_{3}-\mathrm{SiO}_{2} \text { Glass }\end{array}$ \\
\hline $\begin{array}{c}\text { Flexural } \\
\text { strength }\left(\mathrm{kg} / \mathrm{cm}^{2}\right)\end{array}$ & 1500 & 1400 & 1800 & 2000 & 1350 & 1700 & 3500 \\
\hline $\begin{array}{c}\text { Dielectric } \\
\text { constant }(1 \mathrm{MHz})\end{array}$ & 5.0 & 3.9 & 4.9 & 6.1 & 8.5 & 5.6 & 7.5 \\
\hline Dissipation factor & $0.5 \%$ & - & $0.5 \%$ & $0.2 \%$ & - & $0.1 \%$ & $0.3 \%$ \\
\hline $\begin{array}{c}\text { Thermal Expansion } \\
\text { coefficient }\left({ }^{\circ} \mathrm{C}\right)\end{array}$ & $79 \times 10^{-7}$ & $19 \times 10^{-7}$ & $40 \times 10^{-7}$ & $80 \times 10^{-7}$ & $55 \times 10^{-7}$ & $23 \times 10^{-7}$ & $42 \times 10^{-7}$ \\
\hline
\end{tabular}


さらに微小ビアホール技術などが開発され，ベアチップ や他のチップ部品との混成集積回路を構成し，小型で多 機能なモジュールが開発されつつある。

低温焼結基板材料は，セラミックスーガラス系 $\left(\mathrm{Al}_{2} \mathrm{O}_{3}\right.$ 一ガラス, フォルステライトーガラス等), 結晶化ガラス系 (コージライト系, $\beta$-スポジュメン系等), 複合酸化合物 系 $\left(\mathrm{BaO}-\mathrm{Al}_{2} \mathrm{O}_{3}-\mathrm{SiO}_{2}\right.$ 等) に大別される。 Tab.5 に代表的 低温焼結材料とその特性を示す。一般的にはセラミック スーガラス系が多い。

この材料の応用としては, メモリモジュール，マザー ボード，高周波フロントエンド回路など多岐に及んでい る。

この基板の内藏抵抗としては, $\mathrm{RuO}_{2}$ 材料で抵抗範囲： $100 \Omega \sim 100 \mathrm{k} \Omega / \square, \mathrm{TCR} ： 0 \pm 200 \mathrm{ppm} /{ }^{\circ} \mathrm{C}, \mathrm{Mo}$ 系材 料で抵抗範囲： $10 \Omega \sim 100 \mathrm{k} \Omega / \square, T C R ： 0 \pm 300$ $\mathrm{ppm} /{ }^{\circ} \mathrm{C}$ の特性が得られている10)。

内蔵抵抗をいかに精度良く形成できるか，またはトリ ミングができるかが今後の課題である。

コンデンサ内蔵については後に述べる。

高周波基板としては, 信号の高速処理, クロストーク ノイズの低減，高周波低損失の要求がある。信号の伝搬 遅延時間 $\left(T_{d}\right)$ は, $T_{d}=\varepsilon_{r}{ }^{1 / 2} / c$ で表される。ここで, $\varepsilon_{r}=$ 誘電率, $c=$ 光速である。前述の式から, 信号の高速 処理には低誘電率材料が必要である。また, クロスト一 クノイズは誘電率に比例して大きくなる。以上のことか ら材料としては低誘電率材料が要求される。材料系とし ては, Qurz ガラス-ガラス, コージライトーガラス, $\mathrm{BaO}$ $-\mathrm{Al}_{2} \mathrm{O}_{3}-\mathrm{SiO}_{2}(\mathrm{BAS})$ 等がある。これら材料は, 誘電率が 6 以下で, $\mathrm{Cu}, \mathrm{Ag} / \mathrm{Pd}(\mathrm{Ag}$ 含有率が高い) cofire が可 能である。

主として, 高速コンピュータの CPU 基板として用い られている。この基板は, $\mathrm{Si}$ 半導体のべアチップを実装 するので, Si と同じ熱澎張係数 $\left(3.5 \times 10^{-6} /{ }^{\circ} \mathrm{C}\right)$ をもつ 必要がある。

\section{5 高周波多層デパイス材料 ${ }^{11), 12), 13)}$}

移動体通信，光通信の発展と共に，そこに使用される 電子部品の小型化，高周波化，高信頼性に応えるために 高周波多層デバイス材料がある。

この材料に要求される特性は高誘電率 $\left(\varepsilon_{r}>10\right)$ で誘電 損失が低く，しかも低抵抗材料 $(\mathrm{Cu}$ or $\mathrm{Ag})$ と cofire で きることである。上記の特徵を備える材料として, $\mathrm{BaO}$ $-\mathrm{SrO}-\mathrm{SiO}_{2}-\mathrm{ZrO}_{2}$ 系 $(\mathrm{BSSZ}), \mathrm{CaO}-\mathrm{ZrO}_{2}+$ ガラス $(\mathrm{CZ}$ 系) ${ }^{14)}$ があげられる。その特性は, BSSZ : $\varepsilon_{r}=14, \tan \delta$ $=5 \times 10^{-4}, \quad \mathrm{TCC}<0 \pm 30 \mathrm{ppm} /{ }^{\circ} \mathrm{C}, \mathrm{CZ}$ 系: $\varepsilon_{r}=25$, $\tan \delta=6 \times 10^{-4}, \quad \mathrm{TCC}<0 \pm 10 \mathrm{ppm} /{ }^{\circ} \mathrm{C}$ で, 両材料は Vol.9, No.1

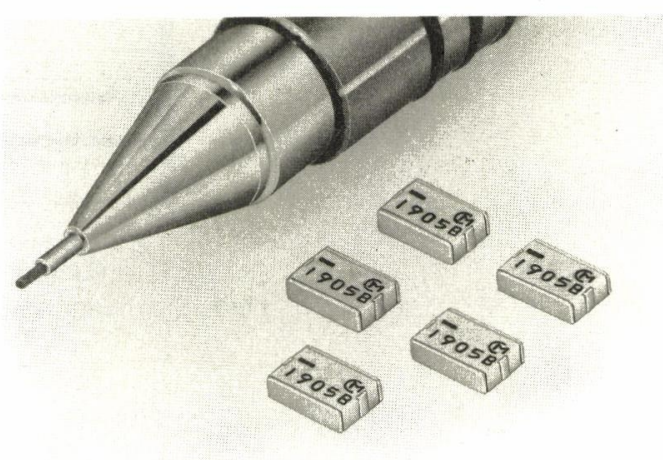

Fig.4 Chip monolithic LC filter.

$\mathrm{Cu}$ と cofire 可能である。

これらの材料の応用としては, 移動体通信（自動車電 話, 携带電話, コードレス電話, MCA ページャ等)の高 周波フィルタがある。

Fig.4 に携带電話用バンドパスフィルタ $(1.9 \mathrm{GHz}$, チ ップ積層フィルタ）を示す。

\section{3 . 誘電体材料の将来の展望}

\section{1 コンデンサ材料}

電子回路の小型化をさらに進めるためには, チップ部 品の実装上の限界があって, 今後は, 厚膜技術と薄膜技 術の融合と, LSI の技術を導入するような方向に展開す るであろう。

\section{1 .1 薄膜材料 ${ }^{15}$}

コンデンサを小型化するひとつの方法として薄膜工法 がある。現在, 薄膜コンデンサ材料としては, $\mathrm{SiO}_{2}$, $\mathrm{TiO}_{2}, \mathrm{Ta}_{2} \mathrm{O}_{5}$ などが使用されている。成膜方法として は, スパッ夕, 蒸着, 陽極酸化等が用いられている。薄 い誘電体膜を使用する場合, 膜中に存在する欠陥の影響 度合いが大きくなり絶縁強度が低下する。そこで, 絶縁 層を複層構造にすることにより欠陥を少なくして安定な コンデンサを形成している。

複層構造のコンデンサの例として，

(1) $\mathrm{Au} / \mathrm{Ta}_{2} \mathrm{O}_{5} / \mathrm{Ta}$

誘電体膜厚 : $2,000 \sim 4,000 \AA$

$\varepsilon_{r}=26, \tan \delta=0.002 \sim 0.010$

TCC : $+200 \mathrm{ppm} /{ }^{\circ} \mathrm{C}$

容量密度: $500 \sim 100 \mu \mathrm{F} / \mathrm{m}^{2}$, 安定性 : $5 \%$

(2) $\mathrm{AuNiCr} / \mathrm{Ta}_{2} \mathrm{O}_{5} / \mathrm{Ta}$, 金属 $/ \mathrm{SiOTa}_{2} \mathrm{O}_{5} / \mathrm{Ta}$ などがある。

チップ HIQ コンデンサの構造を Fig.5 に示す。

薄膜コンデンサはまた, LSI（DRAM 用）に用いられ 


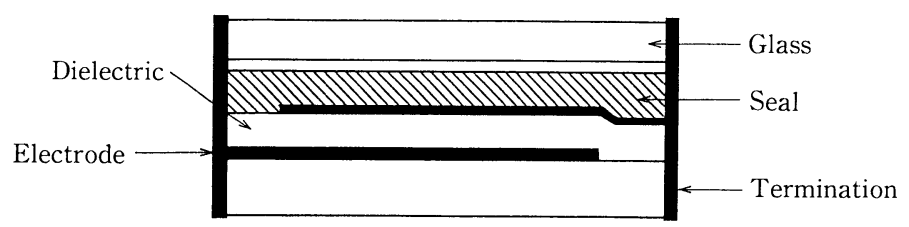

Thichiness of dielectrics

$\left(1.13 \mu \mathrm{m}^{-120 \mathrm{pF})}\right.$

Fig.5 Structure of capacitor made by thin-film method.

る。このコンデンサの材料としては, $\mathrm{SrTiO}_{3}\left(\varepsilon_{r}=230\right.$, $t=53 \mathrm{~nm})$ をイオンビームスパッ夕により作られる ${ }^{16)}$ 。

lMbit 以下の DRAM では, 素子内に形成した $\mathrm{SiO}_{2}$ 薄 膜コンデンサで充分記憶状態を保持できたが, 16 メが以 上の DRAM では，必要な記憶保持力をもたせるために， さらに大きな誘電率をもったコンデンサが要求され，現 在, 高誘電率薄膜材料を Si-DRAM 以上に形成する研究 が精力的に進められている。

\section{1 .2 内蔵コンデンサ材料 ${ }^{17), 18)}$}

電子機器の高密度化, 多機能化を目的に, コンデンサ を内蔵したコンデンサ内蔵多層基板の開発がなされてい る。コンデンサ内蔵の方法としては，グリーンシートで 形成する (シート積層法), 印刷で形成する (印刷法) が ある (Fig.6 参照)。シート積層法は高容量には有利で印 刷法は形成が容易というメリットがある。

シート積層法で使用される誘電体材料には, $\mathrm{Pb}$ 系複合 ペロブスカイト $\left(\varepsilon_{r} \fallingdotseq 3000\right.$, TCC $:+5 \sim-55 \%, \tan \delta<$ $3 \%$ ，容量偏差： $200 \mathrm{nF} \rightarrow 10 \%$ 以下）がある。

印刷法に使用される誘電体材料には, $\mathrm{Pb}$ 系複合ペロブ スカイト $(\mathrm{TCC}:+5 \% \sim 30 \%, \tan \delta=1 \%$, 容量 : 60 $\left.\mathrm{nF} / \mathrm{cm}^{2}\right), \mathrm{BaTiO}_{3}-\mathrm{SrTiO}_{3}$ 系 $\left(\varepsilon_{r}=1,000, \tan \delta=1.2\right.$ \%, TCC： $\pm 15 \%$ ）がある。

内蔵コンデンサも内蔵抵抗と同様，いかに精度良く形 成できるか，またはトリミングができるかが今後の課題 である。

商品への応用として, 水晶発振器, アクティブフィル タ, $\mathrm{VCO}$ 等がある。

また，小スぺース実装という点から，コンデンサはバ
ンプ, ワイヤボンディングによる基板への実装，および コンデンサのネットワーク化が考えられる。このネット ワーク化において考慮すべき点は, コンデンサーコンデン サ間の不要結合容量対策であり，いかに良いアイソレー ションを取るかという点がポイントとなる。

インダクタンスとの複合についての要求も強く, フェ ライト層，誘電体層，絶縁体層とを反応させないで同時 焼成する技術も精力的に行われ，二，三の材質について はすでに成功し，LC 回路モジュールとして量産化され ている ${ }^{19)}$ 。

\section{2 高周波誘電体材料}

高周波の使用周波数帯がミリ波領域 (30 GHz 以上) 広がる中で, 誘電体共振器材料はより大きな $Q \cdot f(\mathrm{GHz})$ の值をもつことを要求される。 $\mathrm{Ba}(\mathrm{Mg} \cdot \mathrm{Ta}) \mathrm{O}_{3}$ を主成分 とした材料が期待されている(現時点では上記材料で $\varepsilon_{r}$ $=25, Q \cdot f=400,000(\mathrm{GHz})$ の值が得られている)。

\section{3 高周波基板材料}

今後，信号の高周波処理をさらに進める中では，半導 体は $\mathrm{Si} よ り \mathrm{GaAs}$ と移行し,これに伴って基板に要求 される特性は以下の通りである。

(1)より低誘電率 $\left(\varepsilon_{r}<3\right)$

(2) $\mathrm{GaAs}$ と同等の熱膨張係数 $\left(4.5 \times 10^{-6} /{ }^{\circ} \mathrm{C}\right.$, 液体 窒素温度～室温)

(3) $\mathrm{Cu}$ or $\mathrm{Ag}$ との cofire が可能

低温焼結材料を用いて誘電率を下げるためにはセラミ ック中に空孔を形成し, GaAs と同等の熱膨張係数を得

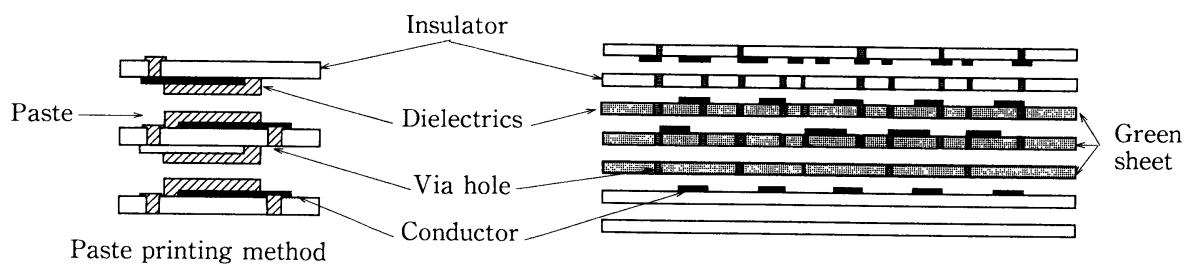

Green sheet method

Fig.6 Typical strucuture of green sheet method and paste printing method ${ }^{17}$ 
るため，セラミック材料組成の再検討がなされる必要が ある。

\section{4 高周波デバイス材料}

今後, 高周波デバイス材料も高周波誘電体材料と同様 小型化, 高周波化のために低損失が要求される。しかし, 高周波デバイス材料は多層構造をもつという特徵から， 低温焼結材料である必要がある。そのため, $\varepsilon_{r}=100$, $\tan \delta=1 \times 10^{-3}(\mathrm{GHz})$ が限界ではないかと考之られ る。

以上のように新しい誘電体セラミックス材料の開発が 進み，それによりさらに広範囲に応用が展開されるであ ろう。

\section{4.まと め}

誘電体材料に要求される特性はいろいろと異なるが, 電子機器部品の動向から考之て，小型化，高容量化，高 周波化，高信頼性化の対応が必要である。

一方, 微小容量のコンデンサは今後 HICに内蔵される と考えられるが, 誘電体セラミックスの開発と実装形態 を踏まえて共存することになるであろう。

\section{参 考 文 献}

1) 坂部行雄：（社）未踏科学技術協会新超伝導材料研究会, NSMF News No.32

2）坂部行雄：化学工業, 第 54 卷第 7 号, p.485 (1990)

3 ） 日本電子工業振興協会：実装材料調査報告 $2, p .191$ (1988)
4）日本マイクロエレクトロニクス協会編：IC 化実装技術, p. 27 (1980)

5 ） 日本電子工業振興協会：実装材料調查報告書 $2, \mathrm{p} .79(1988)$

6 ） 日本電子工業振興協会：実装材料調査報告書 2, p. 85 (1988)

7) NIKKEI ELECTRONICS, 1988 年 8 月 22 日号, p.140.

8 ）脇野喜久男：信学技法, Technical Report of Ieice（1992）

9) H.Mandai et al. : IMC 1986 Proceeding,p.61 (1986)

10）西川敏夫：電気情報関連学会連合大会（1990）

11) New Ceramics, No.2, p.76 (1992)

12）電波新聞, 1991 年 6 月 27 日号

13) H.Mandai et al. : Ceramic Science \& Technology Congree Proceedings, p.391 (1990)

14) H.Mandai et al. : The 3 rd International Ceramic Science \& Technology Congress (1992)

15）日本マイクロエレクトロニクス協会編：IC 化実装技術, 工 業調查会, p.58（1980）

16） NIKKEI MICRODEVICES， 1991 年 6 月 27 日号, p.78

17）上赤日出人：サーキットテクノロジ, Vol.6.No.1, p. 28 (1991)

18）井上芳樹他：第 1 回マイクロエレクトロニクスシンポジウ 厶 (1985 年 7 月, 東京), p.73

19）野村武史：日本セラミック協会, 第 41 回電子材料研究会, p.1 (1990)

\section{〔執筆者紹介〕}

萬代治文（まんだいはるふみ）

昭和 43 年大阪大学基礎工学部卒業。同年秼村田製作所入社。 以来, エレクトロセラミクスの研究, 開発に従事。現在, 多 層商品部部長。

脇野喜久男（わきのきくお）当協会正会員 昭和 25 年大阪大学理学部卒業。同 27 年(侏村田製作所入社, 同 54 年同社専務取締役。現在，同社常任顧問。

工学博士, IEEEフェロー 